\title{
CORRELATIONS BETWEEN SOCIAL ENGAGEMENT AND QUALITY OF LIFE OF THE ELDERLY IN CHINA
}

\section{CORRELACIÓN ENTRE LA IMPLICACIÓN SOCIAL Y LA CALIDAD DE VIDA DE LAS PERSONAS MAYORES EN CHINA}

\author{
Yu PEl peiyu@nau.edu.cn \\ School of Public Economics, Nanjing Audit University. China \\ SRI GunAWAN sgunawan@feb.unair.ac.id \\ Faculty of Economic and Business, Airlangga University. Indonesia \\ SHIEH CHICH-Jen charles@mail.cjcu.edu.tw \\ Department of International Business, Chang Jung Christian University. Taiwan
}

\begin{abstract}
The global aged population and ratio are increasing remarkably that to thoroughly utilize the retired time and enhance the quality of life of the elderly through social engagement is an issue worth exploring. This study aims to understand the current situations of Social Engagement and Quality of Life of the elderly and the differences in distinct background variables as well as discuss the correlations. With a questionnaire survey, residents in the apartments for the aged in Jiangsu Province are sampled as the research participants. A total of 200 questionnaires are distributed, and 157 valid ones are retrieved, with a retrieval rate of $79 \%$. Each collected questionnaire copy was regarded as a valid sample. The research findings show 1. Partially positive effects of Social Engagement on Physiological Health in Quality of Life of the elderly, 2. Significantly positive effects of Social Engagement on the Psychological Condition in Quality of Life of the elderly, 3. Remarkably positive effects of Social Engagement on Social Relationship in Quality of Life of the elderly, 4. Partially positive effects of Social Engagement on Environment Interaction in Quality of Life of the elderly, and 5. Partially moderating effects of demographic variables on the correlations between Social Engagement and Quality of Life of the elderly.
\end{abstract}

\section{KEYWORDS}

Aged society; Environment Interaction; Quality of Life; Social Engagement; Social Relationship.

\section{RESUMEN}

Uno de los temas que merece la pena explorar es el uso del tiempo de jubilación y la mejora de la calidad de vida de los mayores a través de la implicación social dado el notable crecimiento de la ratio global de población anciana. Este estudio trata de entender la situación actual de la implicación social y la calidad de vida de las personas mayores y las diferencias de las distintas variables de fondo, así como la correlación entre ellas. Los participantes en la investigación son residentes de apartamentos para personas mayores de la provincia de Jiangsu a los que se administró un cuestionario. Se distribuyeron 200 cuestionarios, de los que 157 fueron válidos, con una tasa de recuperación del $79 \%$. Cada cuestionario recogido se consideró como una muestra válida. Los hallazgos de esta investigación son los siguientes: 1. Efectos parcialmente positivos de la implicación social en la calidad de la salud fisiológica de los mayores. 2. Efectos positivos significativos de la implicación social en el aspecto psicológico de la calidad de vida de los mayores. 3. Notables efectos 
positivos de la implicación social en las relaciones sociales relacionadas con la calidad de vida de los mayores. 4. Efectos positivos parciales de la implicación social sobre la calidad de vida de los mayores en relación con la interacción con el. 5. Efectos parcialmente moderados de las variables demográficas en la correlación entre implicación social y calidad de vida de los mayores.

\section{Palabras clave}

Calidad de vida; Implicación social; Interacción con el entorno; Relaciones sociales; Sociedad de personas mayores.

\section{INTRODUCTION}

The advance of medicine and societies has prolonged the life expectancy of human beings which have in turn allowed the aged population and the ratio of elderly to nonelderly to significantly increase. The social advance is measured in the United Nations Educational Scientific and Cultural Organization (UNESCO), with the ratio of the elderly above the age of 65 . Countries with an elderly population above $7 \%$ are called the Ageing Country, to which developed countries belong. Societies with an elderly population above $7 \%$ are approaching the Ageing Society. And the ones achieving 14\% are the Aged Society. The others reaching $20 \%$ are the Super Aged Society. The accompanied rapid changes of population structure, no doubt, appear to have great impact on the societies. To cope with and improve the issue of an aged society becomes an inevitable study for the future development of various countries. In the 47th United Nations General Assembly in October of 1992, a ten-year (1992-2001) movement of caring for the elderly was passed by the United Nations, and 1999 was set as the first International Year of Older Persons, which assisted in coping with an ageing society and stressing on the issues of the elderly related to ageing. It tended to create a common society without age differences, through the cooperation of all sectors, to improve the capabilities and value of the elderly engaging in the societies and to eliminate age discrimination. As a result, the aged could actively engage in activities in society to have a healthy and meaningful latter life. The aged are encouraged to plan their latter life with voluntary services, further study, or leisure activities for longer life expectancy and live a free, happy, and dignified life so as to reduce several aged problems. This study therefore intends to understand the current situations of Social Engagement of the elderly in the ageing societies and the effects of the elderly background variables on social engagement.

\section{LITERATURE REVIEW}

\section{Definition of Elderly}

Wu (2010) judged the elderly from the following aspects. (1) Physical Symptoms where the continuously aged would result in moving difficulty, declining sexuality, and reducing activities. (2) Spiritual and Social Life including the growth of their children, the birth of 
the third generation, death of spouse, retirement, loss of family status, forgetting things, and impatience. (3) Psychological Recognition Judgment, the reduction and declination of cognitive judgment, such as loss of thinking, memory declination, and lack of problem solving abilities. Huang (2011) regarded ageing as a unique process, aiming to discuss the social life of the aged from social stratification. The society was classified or leveled by both stratification and age that people at different ages would play distinct roles, power, and obligations. Lee (2011) pointed out the modernization theory as the key factor in the status of the elderly, meaning that with the progress made in modern technology, the life experiences and judgment of the elderly become less useful and thus resulted in the loss of status.

\section{Social Engagement}

Chang (2010) considered community involvement as a dynamic concept and action and the investment in community activities with organized movements, as communities showed unique styles, content, and objectives. Chen (2009) regarded Social Engagement as the process of an individual participating in social activities, actively and automatically investing in social operation, interacting with social members with personal ideas, thinking, and actions, and sharing their social resources of education, culture, religion, recreation, and politics. Su (2011) referred to Social Engagement as the process of an individual devoted to actively participating in social affairs, social communities, activities, and courses, interacting with others, and integrating into their entire life to share with the others. Neugarten (1979) explained the life adjustment of the aged from the aspect of social activity engagement and mentioned that the aged presented normal psychological and social demands then the middle aged did that most of them would keep themselves in the social role activities and were not willing to lose the original "social roles." Consequently, the aged were still active, but with different styles (Hsu \& Tsai, 2012). Kotwal \& Prabhakar (2009) pointed out the premise of activity theory as keeping on activities to enhance physical and mental health and sex life satisfaction. The aged with higher activities would reveal better life satisfaction and problem-solving capabilities, presenting that keeping engaged in social activities with the best conditions in their later life would result in greater life satisfaction.

\section{Quality Of Life}

Gill \& Feinstein (1994) reviewed the literature studies on 75 types of measurements for Quality of Life, where up to $85 \%$ of them did not appear to have obvious differences. Current measurement of Quality of Life tended to be multi-dimensional, including physiological, psychological, and social. Nevertheless, neither one of them aimed to understand the interaction between life situations and individuals (Lin, Yao, Huang \& Wang, 2010; Yao, 2010). 
Holtkamp et al. (2000) pointed out that Quality of Life is an individual subjective judgment, covering perceived, physiological, and psychological functions, self-perception, and perceived security. Sarvimaki (2000) defined Quality of Life as well-being, meaning, and value, with the models of individual intrinsic conditions of health, function, and responses and the extrinsic conditions of physical and socio-cultural environments. Chen (2009) indicated Quality of Life as the dynamic interaction between individuals and environments and the establishment of accordance to achieve favorable life adjustment and individual satisfaction with intrinsic evaluation and extrinsic society. Wang (2010) contained Life Satisfaction in Quality of Life, as Quality of Life was an individual subjective agreement.

\section{Research on Social Engagement and Quality Of Life}

Domestic research on Social Engagement of the elderly presented the significant effects of Quality of Life, Life Satisfaction, Life Adjustment, and Well-Being (Lee, 2010; Su, 2011; Chang, 2010; Kao, 2009; Chen, 2009). Highly Social Engagement appeared in negative correlations with suicide ideation that Social Engagement actually could enhance the effectiveness of Quality of Life (Chang, 2010). Social Engagement and Quality of Life of retired teachers revealed positive correlations that the enhancement of Social Engagement could establish active Quality of Life (Su, 2011). Tsai (2011) discovered the remarkable correlations between Social Engagement and Social Capital, which could effectively enhance Social Engagement and Quality of Life of the elderly.

Based on the relevant research results, the demographic variables affecting Social Engagement of the elderly contain gender, age, marital condition, residential situation, and educational background. Since such variables could directly affect the intention of the social activity engagement of the elderly and indirectly influence their lives, they are covered in this study for the following hypotheses.

H1: Social Engagement shows significantly positive effects on Physiological Health in Quality of Life.

H2: Social Engagement appears remarkably positive effects on Psychological Condition in Quality of Life.

H3: Social Engagement presents notably positive effects on Social Relationship in Quality of Life.

H4: Social Engagement reveals significantly positive effects on Environment Interaction in Quality of Life.

H5: Gender appears remarkable effects on the correlations between Social Engagement and Quality of Life.

H6: Age shows notable effects on the correlations between Social Engagement and Quality of Life.

H7: Marital condition presents significant effects on the correlations between Social Engagement and Quality of Life. 
H8: Educational background reveals notable effects on the correlations between Social Engagement and Quality of Life.

H9: Residential situation shows notable effects on the correlations between Social Engagement and Quality of Life.

\section{RESEARCH METHOD}

\section{Research Framework}

Summarizing the above literature studies, the conceptual framework is proposed in this study (Fig. 1) to discuss the correlations among demographic variables, Social Engagement, and Quality of Life.

\section{Measurement of Research Variables}

\section{Social Engagement}

Social Engagement is divided into paid human resource applications and unpaid community involvement (Chang, 2010). The latter is applied to this study. Referring to Chang (2010), Social Engagement covers four dimensions. 1. Learning Activities. The learning contents of the aged contain organized Learning Activities provided by non-formal education, where the aged could increase their knowledge, enhance health, cultivate delight of life, and reinforce future Life Adjustment. 2. Voluntary Services. With free will, rather than through personal obligation or legal responsibilities, the aged can provide support for others, organizations, communities, and societies through the arrangement of institutes or self-contact, without any material rewards, to enhance the efficacy of public affairs and promote the image of social benefits. 3. Religious Activities. The aged can actively participate in organizational meetings of Buddhism, Taoism, Christianity, Catholicism, and Islam or religious activities, like worship and prayer. 4. Leisure Activities, indicating individuals, in their free time, can actively participate in sports and tours held by organizations or groups.

\section{Quality of Life}

From the above opinions, the aged cannot simply consider the physiological problems, after the retirement, but also the social, environmental, and psychological perception, which could further influence their quality of life. The discussion of Quality of Life of the aged should therefore be integral, including physiology, psychology, and spirit, and the aged is treated as "a whole" to enhance the quality of life. According to the coverage of Quality of Life in the World Health Organization (2012), the following dimensions are concluded in this study. 1. Physiological Health includes physical symptoms, action and work abilities, 
caring responsibility abilities, sleep and rest conditions, and dependence on drugs and medicine. 2. Psychological Condition contains life satisfaction, life goal achievement, life control, internal emotion, and opinions of belief and self-appearance. 3. Social Relationship covers interpersonal relationships, actual social support, sex life satisfaction, and the degree of being respected and accepted. 4. Environment Interaction includes personal physical safety and guarantee, residential environments, financial resources, and acquisition and quality of health and social healthcare, opportunities of acquiring new information and skills, chances of participating in entertainment and leisure activities, and the effects of the physical environment pollution, noise, transportation, and climate.

\section{Research Subject}

Apartments for the aged, as the symbolized project for economic and social development in Jiangsu Province, are the province government's public beneficial construction for the demands of the retired aged from institutes and colleges in the Jiangsu Province. The buildings contain apartments, medical healthcare centers, leisure activity centers, and service administration areas and facilities. Additionally, the apartments are established emergency green channels with several large-scale hospitals in Nanjing; and, a level-2 rehabilitation hospital will be built for the rehabilitation of the aged. Apartments for the aged in Jiangsu Province therefore are selected as the research subject.

\section{Data Analysis of Research Samples and Sampling}

The questionnaires are distributed and collected on-site. A total of 200 questionnaires were distributed to the residents in the apartments for the aged in Jiangsu Province, and 157 valid ones were retrieved, with a retrieval rate of $79 \%$. Each collected copy was regarded as an effective sample. The collected data are analyzed with SPSS, including Factor Analysis, Reliability Analysis, Regression Analysis, and Analysis of Variance, to test the hypotheses.

Figure 1.

Research framework

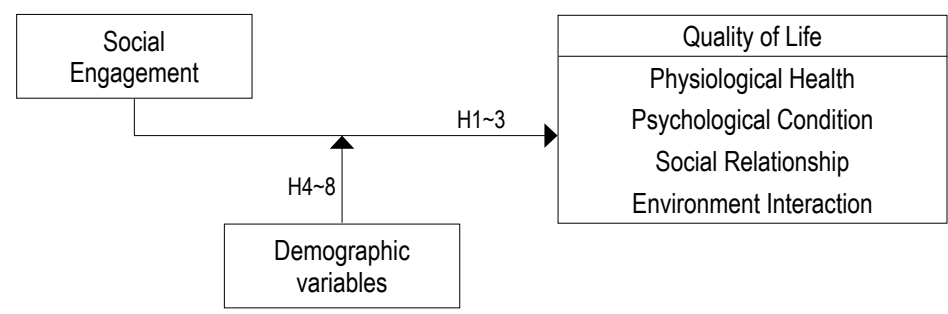




\section{AnALYsis}

Factor Analysis with Principal Components Analysis is applied in this study. Varimax is selected for the orthogonal rotation, and the factors with the eigenvalue larger than 1 are selected as the variables in the formal questionnaire. Applying Item Analysis and Factor Analysis to constructing the validity, the questionnaire is further preceded the reliability analysis. The Cronbach a coefficient is acquired with the internal consistency for understanding the internal consistency and reliability of the questionnaire. Regression Analysis is also utilized for understanding the correlations between social participation and quality of life, and Analysis of Variance is further applied to discussing the effects of demographic variables on social participation and quality of life.

\section{RESEARCH RESULTS AND ANALYSIS}

\section{Factor Analysis}

With Factor Analysis, Social Engagement was extracted into four factors of Learning Activities (eigenvalue=3.238, $a=0.83$ ), Voluntary Services (eigenvalue=2.446, $a=0.87$ ), Religious Activities (eigenvalue=2.052, $\alpha=0.83$ ), and Leisure Activities (eigenvalue=1.517, $\mathrm{a}=0.82$ ). The covariance explained achieved $78.325 \%$.

With Factor Analysis, Quality of Life was extracted into the four factors of Physiological Health (eigenvalue=2.831, $\alpha=0.84$ ), Psychological Condition (eigenvalue=2.291, $\alpha=0.86$ ), Social Relationship (eigenvalue $=1.732, \alpha=0.81$ ), and Environment Interaction (eigenvalue=1.215, $\alpha=0.88$ ). The covariance explained achieved $81.644 \%$.

\section{Correlation Analysis of Social Engagement and Quality Of Life}

Correlation Analysis of Social Engagement and Physiological Health in Quality of Life

Applying Regression Analysis to testing $\mathrm{H} 1$, Table 1 , the analyses showed the significant effects of Learning Activities ( $\beta=1.527, p=0.041$ ), Religious Activities ( $\beta=1.976, p=0.013$ ), and Leisure Activities ( $\beta=2.237, p=0.002$ ) on Physiological Health in Quality of Life which proved that $\mathrm{H} 1$ was partially supported.

Correlation Analysis of Social Engagement and Psychological Condition in Quality of Life

Applying Regression Analysis to testing $\mathrm{H} 2$, Table 1 , the analyses presented remarkable effects of Learning Activities ( $\beta=1.681, p=0.035)$, Voluntary Services $(\beta=1.862, p=0.018)$, Religious Activities ( $\beta=2.073, p=0.008)$, and Leisure Activities $(\beta=2.132, p=0.005)$ on Psychological Condition in Quality of Life which demonstrate that $\mathrm{H} 2$ was supported. 
Correlation Analysis of Social Engagement and Social Relationship in Quality of Life

Utilizing Regression Analysis for testing $\mathrm{H} 3$, Table 1 , the analyses revealed notable effects of Learning Activities ( $\beta=1.925, p=0.016)$, Voluntary Services $(\beta=2.341, p=0.000)$, Religious Activities ( $\beta=1.577, p=0.037)$, and Leisure Activities $(\beta=2.469, p=0.000)$ on Social Relationships in Quality of Life to depict that H3 was supported.

Correlation Analysis of Social Engagement and Environment Interaction in Quality of Life

Utilizing Regression Analysis for testing $\mathrm{H} 4$, Table 1 , the analyses appeared to have significant effects of Voluntary Services ( $\beta=1.762, p=0.026)$ and Leisure Activities $(\beta=2.316$, $\mathrm{p}=0.000$ ) on Environment Interaction in Quality of Life which illustrate that $\mathrm{H} 4$ was partially supported.

\section{Moderating Effects of Demographic Variables}

\section{Effects of gender on the relations between Social Engagement and Quality of Life}

With Analysis of Variance, the empirical results, Table 2, showed remarkable effects of gender on the correlations between Learning Activities, Religious Activities, Leisure Activities and Physiological Health, between Voluntary Services, Religious Activities and Psychological Condition, between Religious Activities, Leisure Activities and Social Relationships, and between Learning Activities, Voluntary Services and Environment Interaction which implied that $\mathrm{H} 5$ was partially supported.

\section{Effects of age on the relations between Social Engagement and Quality of Life}

With Analysis of Variance, the empirical results, Table 2, presented the notable effects of age on the correlations between Learning Activities, Religious Activities, Leisure Activities and Physiological Health, between Voluntary Services, Religious Activities and Psychological Condition, between Learning Activities, Religious Activities, Leisure Activities and Social Relationship, and between Learning Activities, Voluntary Services and Environment Interaction which showed that $\mathrm{H} 6$ was partially supported.

Effects of marital condition on the relations between Social Engagement and Quality of Life

With Analysis of Variance, the empirical results, Table 2, exhibited the effects of marital condition on the correlations between Voluntary Services, Leisure Activities and Physiological Health, between Learning Activities, Voluntary Services, Religious Activities and Psychological Condition, between Voluntary Services, Leisure Activities and Social Rela- 
tionship, and between Leisure Activities and Environment Interaction which displayed that $\mathrm{H} 7$ was partially supported.

Effects of educational background on the relations between Social Engagement and Quality of Life

With Analysis of Variance, the empirical results, Table 2 , revealed the effects of educational background on the correlations between Learning Activities, Voluntary Services and Physiological Health, between Learning Activities, Voluntary Services and Psychological Condition, between Learning Activities, Voluntary Services and Social Relationship, and between Learning Activities, Leisure Activities and Environment Interaction to show that H8 was partially supported.

Effects of residential situation on the relations between Social Engagement and Quality of Life

With Analysis of Variance, the empirical results, Table 2, presented the effects of residential situation on the correlations between Learning Activities, Religious Activities and Physiological Health, between Religious Activities, Leisure Activities and Psychological Condition, between Learning Activities, Voluntary Services, Leisure Activities and Social Relationship, and between Learning Activities, Voluntary Services, Leisure Activities and Environment Interaction which supported that $\mathrm{H} 9$ was partially supported.

Table 1.

Regression Analysis of Social Engagement and Quality of Life

\begin{tabular}{|c|c|c|c|c|c|c|c|c|}
\hline Dependent variable $\rightarrow$ & \multicolumn{8}{|c|}{ Quality of Life } \\
\hline Independent variable $\downarrow$ & \multicolumn{2}{|c|}{$\begin{array}{c}\text { Physiological } \\
\text { Health }\end{array}$} & \multicolumn{2}{|c|}{$\begin{array}{c}\text { Psychological } \\
\text { Condition }\end{array}$} & \multicolumn{2}{|c|}{$\begin{array}{c}\text { Social } \\
\text { Relationship }\end{array}$} & \multicolumn{2}{|c|}{$\begin{array}{l}\text { Environment } \\
\text { Interaction }\end{array}$} \\
\hline Social Engagement & $\beta$ & $\rho$ & $\beta$ & $\rho$ & $\beta$ & $\rho$ & $\beta$ & $\rho$ \\
\hline Learning Activities & $1.527^{*}$ & 0.041 & $1.681^{*}$ & 0.035 & $1.925^{*}$ & 0.016 & 0.943 & 0.631 \\
\hline Voluntary Services & 1.233 & 0.297 & $1.862^{*}$ & 0.018 & $2.341^{* *}$ & 0.000 & $1.762^{*}$ & 0.026 \\
\hline Religious Activities & $1.976^{*}$ & 0.013 & $2.073^{* *}$ & 0.008 & $1.577^{\star}$ & 0.037 & 1.436 & 0.089 \\
\hline Leisure Activities & $2.237^{\star \star}$ & 0.002 & $2.132^{\star \star}$ & 0.005 & $2.469^{\star *}$ & 0.000 & $2.316^{\star \star}$ & 0.000 \\
\hline $\mathrm{F}$ & \multicolumn{2}{|c|}{22.458} & \multicolumn{2}{|c|}{28.762} & \multicolumn{2}{|c|}{34.183} & \multicolumn{2}{|c|}{42.648} \\
\hline Significance & \multicolumn{2}{|c|}{$0.000^{* * *}$} & \multicolumn{2}{|c|}{$0.000^{* * *}$} & \multicolumn{2}{|c|}{$0.000^{* * *}$} & \multicolumn{2}{|c|}{$0.000^{\star \star *}$} \\
\hline R2 & \multicolumn{2}{|c|}{0.197} & \multicolumn{2}{|c|}{0.238} & \multicolumn{2}{|c|}{0.291} & \multicolumn{2}{|c|}{0.346} \\
\hline Adjusted R2 & \multicolumn{2}{|c|}{0.018} & \multicolumn{2}{|c|}{0.025} & \multicolumn{2}{|c|}{0.031} & \multicolumn{2}{|c|}{0.038} \\
\hline
\end{tabular}

Note: * stands for $p<0.05,{ }^{* *}$ for $p<0.01$

Data source: Self-organized in this study 
Table 2.

Demographic variables on the relations between

Social Engagement and Quality of Life

\begin{tabular}{|c|c|c|c|c|c|}
\hline $\begin{array}{l}\text { Demographic } \\
\text { variables }\end{array}$ & $\begin{array}{c}\text { Social } \\
\text { Engagement }\end{array}$ & $\begin{array}{c}\text { Physiological } \\
\text { Health }\end{array}$ & $\begin{array}{c}\text { Psychological } \\
\text { Condition }\end{array}$ & $\begin{array}{c}\text { Social } \\
\text { Relationship }\end{array}$ & $\begin{array}{l}\text { Environment } \\
\text { Interaction }\end{array}$ \\
\hline \multirow{4}{*}{ Gender } & Learning Activities & 0.024 & 0.214 & 0.183 & 0.011 \\
\hline & Voluntary Services & 0.162 & 0.036 & 0.337 & 0.016 \\
\hline & Religious Activities & 0.032 & 0.004 & 0.042 & 0.415 \\
\hline & Leisure Activities & 0.002 & 0.625 & 0.000 & 0.332 \\
\hline \multirow{4}{*}{ Age } & Learning Activities & 0.000 & 0.227 & 0.016 & 0.004 \\
\hline & Voluntary Services & 0.523 & 0.003 & 0.223 & 0.035 \\
\hline & Religious Activities & 0.022 & 0.042 & 0.017 & 0.533 \\
\hline & Leisure Activities & 0.018 & 0.075 & 0.038 & 0.762 \\
\hline \multirow{4}{*}{$\begin{array}{l}\text { Marital } \\
\text { condition }\end{array}$} & Learning Activities & 0.196 & 0.008 & 0.058 & 0.112 \\
\hline & Voluntary Services & 0.014 & 0.031 & 0.000 & 0.087 \\
\hline & Religious Activities & 0.216 & 0.044 & 0.124 & 0.091 \\
\hline & Leisure Activities & 0.039 & 0.096 & 0.015 & 0.034 \\
\hline \multirow{4}{*}{$\begin{array}{l}\text { Educational } \\
\text { background }\end{array}$} & Learning Activities & 0.028 & 0.007 & 0.000 & 0.046 \\
\hline & Voluntary Services & 0.005 & 0.023 & 0.000 & 0.162 \\
\hline & Religious Activities & 0.062 & 0.415 & 0.064 & 0.433 \\
\hline & Leisure Activities & 0.433 & 0.283 & 0.715 & 0.037 \\
\hline \multirow{4}{*}{$\begin{array}{l}\text { Residential } \\
\text { situation }\end{array}$} & Learning Activities & 0.036 & 0.517 & 0.013 & 0.001 \\
\hline & Voluntary Services & 0.192 & 0.056 & 0.022 & 0.037 \\
\hline & Religious Activities & 0.017 & 0.012 & 0.364 & 0.227 \\
\hline & Leisure Activities & 0.094 & 0.043 & 0.000 & 0.002 \\
\hline
\end{tabular}

Data source: Self-organized in this study 


\section{Suggestions}

The following suggestions are proposed in this study.

To provide diverse Leisure Activities, reinforce promotion, and encourage the elderly engagement with partners

The research results present the most obvious effects of Leisure Activities Engagement on Quality of Life of the elderly. It is therefore suggested that the government should build completely dynamic leisure facilities and reinforce the maintenance of outdoor leisure sites. Furthermore, local characteristics should be integrated with the promotion of local leisure industries, such as ecotourism, festival tours, and experiential tours, for the elderly to engage in deeper Leisure Activities and acquiring physical and mental satisfaction by participating in dynamic activities to achieve physical, mental, and spiritual development. It is also suggested that the elderly could engage in activities with partners so that they are willing to participate in social activities, Social Engagement of the elderly would be more successful, and Quality of Life could be enhanced.

\section{To pay attention to the healthcare of the elderly for enhancing Social Engagement and promoting Quality of Life}

The elderly need to have healthy bodies to do whatever they intend to do and possess control in their lives. Nevertheless, physical ageing is inevitable that they should accept the nature of ageing and face life with active and positive attitudes. As a consequence, the government is suggested to arrange healthcare or self-caring courses for the elderly in widely receiving health knowledge, cultivating regular lifestyles and exercise, paying attention to diet and nutrition, regularly doing health checks, and establishing correct medical attitudes and behaviors for a healthy lifestyle. When the elderly are healthy, they could continuously participate in social activities and present excellent Quality of Life.

\section{To encourage the engagement in Voluntary Services, feedback and contribution to societies for promoting Quality of Life}

The elderly appear to have comparatively negative actions on Voluntary Services that they should be encouraged to positively develop abilities for compensating the losing status or physical activities. It is suggested that the government should provide the elderly with some suitable jobs in order to thoroughly reutilize these human resources and establish self-achievement for the Psychological Condition of the elderly. Devoting oneself to the society and acquiring self-fulfillment would be helpful for latter life happiness and wellbeing. 


\section{CONCLUSION}

From the research results, Table 2, the more successful social participation could better enhance quality of life that social participation, as a key variable to predict the quality of life, presents positive effects on quality of life. Nevertheless, there are little research on the correlations between social participation and quality of life of the aged. Besides, the research on social participation tends to single dimension, such as voluntary service, further study, and leisure activity, that studies on multi-dimensional social activities are insufficient. The research results show the demographic variables affecting the social participation of the aged covering gender, age, marital status, residential condition, main source of income, educational background, perceived health condition, and religious belief. As the social participation of the aged could be affected by such variables, it would directly influence the intention of the aged to participate in social activities and result in effects on the quality of life.

\section{ACKNOWLEDGMENTS}

The essay is the periodicity fruit of the Humanities fund project from the Education Ministry of China (NO. 13YJA790089 Research About Real Estate Tax Policy Effects by CGE Model)

\section{REFERENCES}

Chang, Mei-ling. 2010. "A study of self-Concept, social engagement, and suicide ideation among the elderly." Student Affairs Research 33(2):7-20.

Chang, Yi. 2010. "Factors in Social Engagement of the aged." Journal of Community Development 103: 225-235.

Chen, Yu-yuan. 2009. "Retirement Elementary School Retires a Teacher's Society to Participate and The Related Quality of Life Study." Journal of Community Development 21: 77-87.

Holtkamp, C. C. M., Kerkstra, A., Ribbe, M. W., Campen, C., \& Ooms, M. E. 2000. The relation between quality of co-ordination of nursing care and quality of life in Dutch nursing home. Journal of Advanced Nursing, 32(6), 1364-1373.

Hsu, Li-chun \& Tsai, Wen-hui. 2012. Aging Sociology. Taipei City: Chu Liu.

Kao, Ying-fang. 2009. Study on the relationship between Retirement Planning, Social Participation and Life Adaptation of the Elementary School Retired Teachers in Yunlin County. Taipei City Lifelong Learning Newsletter, 38:8-16.

Kotwal, N., \& Prabhaker, B. 2009. Physical needs and adjustments made by the elderly. Stud Home Comm, 3(2): 115-121. 
Lee, Tsung-pai. 2011. "Ageing theory and healthcare of the aged." Journal of Disability Research 2(2): 77-94.

Lee, Zai-fa. 2010. The correlation study of elementary retired teacher's social participation, social support and life satisfaction. Formosa Journal of Mental Health 3(1): 169-181.

Lin, Mao-Jung, Yao, Kai-ping, Huang, Jing-hsiang \& Wang, Jung-te. 2010. "Scale Descriptor Selection for Taiwan-version of Questionnaire of World Health Organization Quality of Life." Chinese Journal of Public Health 18(4): 262-270.

National Academy for Educational Research. 2011. Encyclopedic Dictionary of Eduation. Browsed at http://edic.nict.gov.tw.

Neugarten, B. L. 1979. Time, age, and the life cycle. American Journal of Psychiatry, 136: 887-894.

Rose, A. M. 1965. The subculture of aging: A frame work for research. Philadelphia: Davis.

Su, Wan-ling. 2011. "A Study of the Relationship between Social Participation and Attitude toward Aging of the Retired Teachers." Taiwan Economic Forum 6(2): 62-81.

Sarvimaki, A. 2000. Quality of life in old age described as a sense of well-being, meaning and value. Journal of Advanced Nursing, 32(4):1025-1033.

Tsai, Ming-chan. 2011. A Study of the Relationships between Social Capital and Social Participation for Older Adults. Journal of Ching Kuo Institute of Management and Health, 29: 29-39.

Wang, Hui-ling. 2010. Correlations between community caring concern centers and Quality of Life of the aged. The Journal of Social Development, 95: 7-19.

World Health Organization. 2011. "Introduction to the Development of the WHOQOL-Taiwan Version." Chinese Journal of Public Health 19(4): 315-324.

Wu, Lao-te. 2010. Theory and practice of aged society. New Taipei City: New Wen Ching Developmental Publishing.

Yao, Kai-ping. 2010. Introduction to the Concepts and Measurement of Health-Related Quality of Life. Formosan Journal of Medicine, 6(2):183-192.

Yao, Kai-ping. 2012. "Questionnaire development and application of Taiwan-version World Health Organization Quality of Life." Formosan Journal of Medicine 6(3): 193-200.

DR. Yu PEl is a professor in the School of Public Economics, Nanjing Audit University Zhonghe Building, 86 West Yushan Road, Pukou District, Nanjing, China. He received his PhD degree in the Shanghai University of Finance and economics. His research interests are focused on Taxation theory and policy, government procurement theory, financial risk, and fiscal expenditure performance evaluation.

DR. SRI GunaWAN is a program director in the Master of management Program \& Head, Department of Management, Faculty of Economic and Business at Airlangga University, Indonesia Jalan Airlangga No.4 Surabaya, 60286 Indonesia. His research interests are centered in Organizational behavior, Consumers Behavior, and Marketing. 
Dr. ShieH, Chich-Jen is a Professor in the Department of International Business, Chang Jung Christian University, Taiwan, No.1, Changda Rd., Gueiren District, Tainan City 71101, Taiwan. His researches interested are focused on International marketing Management, International Human Recourse Management, and Operational and Production Management.

RECEIVED: 15 August 2013.

ACCEPTED: 23 March 2014.

PUBLISHED ONLINE: 26 June 2014. 